\title{
Towards a Language-Oriented Approach to Human Cognition
}

\section{Edmond Cane}

\author{
Phd Candidate, Institute of Albanological Study, Albania
} Email: ecane2000@yahoo.com

\section{Doi:10.5901/ajis.2015.v4n2s2p176}

\begin{abstract}
Cognitive psychology is surely regarded very close and relevant to linguistic studies and psycholinguistics, to some extent, puts the two together. Despite this long tradition of co-sitting, the language side has been somehow inferior, generally receiving contributions from cognitive psychology and rendering less of its own. The implicit reading in this article is that language can provide very insightful perceptions regarding human cognition and that language-oriented approach to the structure and the development of human cognition should be considered instead. Language could be the ground that important theories have been evaluated and tested. Further, advanced research in language studies may 'fire back' and provide clues to the structuring and the establishment of human cognitions structures.
\end{abstract}

Keywords: linguistics, psycholinguistics, cognitive psychology, constructivism;

\section{The need for reliable epistemological ground in language research}

The language structures need to be explored and their patterns will have to be retried. Language has long been a specific challenge because research into language can hardly be tested or tried against any proof or evidence. Our brain is still kind of 'locked' for any evidence regarding the language structure and language processing. Nowadays there is growing need for language research to address, in a reliable way, concepts and constructions already established in cognitive psychology and neurosciences, about the structuring and the establishment of such structures in our brain. Language models and patterns should fit into the neurobiological models and patterns as the closest and the most reliable support and confirmation that we actually avail of.

Research into language grammar and more particular issues relating to the category and categorical matter has shown that it needs deeper insight, such that is generally associated with cognitive psychology and neurosciences, for questions like:

- What are the necessary conditions for our cognition?

- What are the resources?

- What makes our arguments verifiable and reliable?

For quite a long time, the language structures are taken for granted, and the main theories have basically focused on the derivations and transformations and the rules such kind of algorithm. Recent evidence is 'suggesting' that the structures themselves could be the key to answering such questions, i.e. instead of the proposition of rules coming from the so-called pre-wired universals that control and rule the structures, the job may be done by the pattern and the matter inside the structures.

The traditional grammar has observed categories in an ambiguous context, incapable of proving that these have an idiosyncratic character, so as to justify the representational name these have been attached. Coherence seems to be the Achilles Heel. It is common to find in all texts aligning with traditional pattern of thinking that for instance, the Simple Present tense has a long list of meanings or uses, that are typically found or belong to other Tenses; uses that are typical for Present Continuous, for Future Tense, for Past Tense (Akademia e Shkencave, 2002); (Palmer F. R., 1974). Despite this incoherence, all speakers have sufficient competence to adequately use and manipulate very sophisticated structures, frames, links etc., in highly complex, competent and highly constrained contexts. The description of the structures is absolutely incompatible with the highly constrained and sophisticated language use.

Later findings and research bought up important clues to the pattern of the grammatical structures. An important start was with Saussurean approach to consider language as a complex structure, consisting of linguistic signs. Compared to the traditional concept of 'word', the linguistic sign marks an attempt for deeper insight into what was mostly taken for granted. The linguistic sign is at the bottom of language structure, as an organic link of the signifier (the graphic 
or sound matter of an element) and the signified (the 'piece' of thought entrapped by a particular signifier).

Sausure and other structuralist authors (Martinet, Jacobson, Hjelmslev) did not research much into grammar area. The concept of linguistic sign was launched and established as the basic brick of this theory, and illustrated mainly in phonetics and semantics. Grammar was rather a 'hard nut' in many respects.

The concept of 'linguistic sign' or 'element' seriously questions the basics of traditional grammar and demand that the basic concept should be reconsidered and re-evaluated. A particular grammatical element like Present Tense, Past Perfect, or the nominative case, requires a particular identity, that is coherent in itself, that is specific, idiosyncratic. Here comes the challenge of ruling and disciplining the variety list of many grammatical categories, which, for the language speakers are felt to have a particular identity. This is what the linguist must grasp and describe.

Language structures are knowledge structures. These could be considered as primitive constructions and as such may offer clues to more advanced and sophisticated structures which 'fall under' psychology. Positing it as such, it implies that the pattern established for language structures should be compatible with the patterns established and claimed by cognitive psychology.

So far, it has been the cognitive psychology to suggest and to highlight the directions and the inclinations for linguistics, acknowledging some kind of autonomy for language, some kind of border it has refrained itself from crossing. However, considering language structures as primary knowledge structures, not simply linguistic or syntactic structures, implies that such border needs to be crossed, and with it comes the responsibility to have compatible patterns and concepts for the language and knowledge structures - and there is quite a gap at the moment, together with some unwillingness to consider this gap.

In addition, another important direction is to have the pattern of grammatical structures responsible for or compatible with the patterns established by neurosciences. The three need to provide deeper insight so that their respective structures if not fully compatible, should be at least communicating vessels, such that their processing fits in with within a greater picture of the processing of our brain.

\section{Constructivism and inneism on epistemological basis of cognition}

Piaget's constructivism and Chomsky's inneism have been important moments in cognitive psychology. They provide opposite alternatives regarding the establishment of cognitive structures in general and language structures in particular. The two approaches have encouraged long-time research, propositions and the debate between the two still remains hot. ${ }^{1}$ As Piatelli-Palmerini points out, 'the well-known theory of cognitive development elaborated by Piaget and the equally famous theory of generative grammars elaborated by Chomsky were being compared more and more frequently - sometimes in terms of opposition, sometimes in terms of complementarity' (Piatelli-Palmerini, 1980, p. xvi)

As the term itself suggests, constructivism posits that cognition structures are constructed through the processes in which the individuals is involved. Human cognition proceeds through equilibrium, turbulence and the re-establishment of the new equilibrium. The new equilibrium involves the patterns of assimilation and accommodation, which 'push' the structures into more complex and advanced levels, thus accounting why and how our cognitive structures develop and become more complex.

The concept is well-known, but, in the detailed analysis and examination of the language structures, this needs to be experimented and tried yet. There is quite a gap between the theoretical general linguistics which may link to cognitive psychology, and the concrete language analysis. Although this view has been hotly contested by generativists, in most part it is yet not widely known in linguistics and, while there is not much evidence in support, there is not much evidence against it.

With regard to evolution approach, Piaget is between Lamarckism (evolution based on internal structures) and Darwinism (evolution directed through natural selection, highlighting the role of the outer environment), in search of a third alternative. Piaget believes that the turbulence is provided from the outer environment, and affects the process through fluctuations. The latter are accommodated to varying scales into the newly developed structures of re-equilibrium. These themes provide for selective strategies, which carry and deliver particular patterns.

One important theme posited by constructivism is auto-regulation, which Piaget seems to offer as the third alternative as opposed to Lamarckism and Darwinism. Our cognition is thus a mechanism of such auto-regulation and an

${ }^{1}$ A direct debate was organized in 1975, at Royaumont Abbey (France), including Piaget and Chomsky, as well as well known scientists in linguistics, psychology, biology etc. It has been presented by this author (Piatelli-Palmerini). 
output of this auto-regulation at the same time.

Constructivism and generativism employ two ontological concepts: the crystal (the solid specific structures) and the flame (the constant activity of external forms, independent of internal processes). The scientific dilemma is whether the development proceeds on the basis of the pre-wired structures, programmed to develop as they do (the inneistic approach) or the development flows through a process of auto-regulation and self-organization (the constructivist approach).

\section{Inneism and Generativism}

For inneists, all regulation regarding order, organization, structuring, be it biological, cognitive or linguistic, comes internally, and is inborn. Order can not be imposed externally. It is done through the execution of pre-wired programs. Right from the start, the species contains the 'envelope' of opportunities, and the construction plan stems from therein. There can be no transfer of structure from the outer environment, from the macro- to the micro-structures' (PiatelliPalmerini, 1980).

The environment can not impose its own structure to the living organisms. The latter themselves determine which features will be transferred and accommodated from the external environment. Chomsky posits that there is no assimilation or interiorization of structures outside the individual organism. The latter possesses essential universals which enable the establishment of specific features (parameters) ${ }^{2}$ applied and actualized after exposure to the data from the environment. The language structures are so claimed to develop in the human individuals. As Jacob ${ }^{3}$ highlights, there is no regulation but based on structures and with structures which exist for this regulation. The regulation occurs between two structures, the one which regulates and the one which is regulated, both established prior to regulation.

Some propositions of inneistic biology, which spread further to psychology and language, are:

- Auto-regulation is done by structures which are internal and these regulate smaller variations

- Regulation can not anticipate the constitution of regulatory structure genetically determined

- Individual experiences can not be incorporated in genes.

Inneism tried the basic challenging questions like: 1) What is it that we know, when we know a language? (2) How is this knowledge acquired? (3) How is this knowledge put to use? (4) What is the physical basis, in neural mechanisms, for the systems of knowledge and use of language (Chomsky, 1987). While focusing on the first three question, Chomsky admits that "the fourth question remains on the horizons of research".

Generativism (and inneism) is being more and more contested nowadays. Per Linell (2011), argues that language has been established by our brain in the evolutionary way, that it has not been pre-programmed or pre-wired. Language faculty consists of aggregate faculties interlinked. Language structures relate to communication and practices that carry meaning. But generativism has worked out a rather dehumanized system of abstract symbols. As such, generativism has gone too radical to negate the very relevance of language use. From the evolution angle, Chomsky disagrees with Darwinism. The language faculty is not one in terms of evolution or natural selection. For him, language faculty is a given fact. The Universal Grammar is not adaptive in nature (Harnad, 2008).

Per Linell also questions the methodology on which generativism relies - the intuition. The Universal Grammar has been introduced so abstract, it can not be tested, indentified, nor can it be observed in the linguistic data and facts. It has to be drawn from the linguists' intuition - which is far from being a reliable pattern of research. Finally Per Linell observes that Chomsky did not discover - he invented Universal Grammar.

\section{Alternative developments in linguistics}

At the time of the debate between Chomsky and Piaget, Piatelli-Palmarini stated that there had been no development of any constructivist grammar until then (Piatelli-Palmerini, 1980, p. viii). However, today generativism is no more that enthusiastically appreciated, and on the other hand, new views have emerged: construction grammar ${ }^{4}$, frame semantics, connectionism.

\footnotetext{
2 In later publication, universals are referred to as "principles" and the specific structures which are then developed become "parameters"

${ }_{3}^{3}$ Pierre Jacob - http://www.institutnicod.org/membres/membres-statutaires/jacob-pierre/?lang=fr

${ }^{4}$ An earlier version was the Linguistic Gestalt e Chicago Linguistic Society, 1977. Main authors: George Lakoff, Adele Goldberg, etc.
} 
Earlier reference to the above debate can be implicitly found in authors like Saussure, Sapir, Bloomfield, Martinet, etc.

\section{The early contribution of structuralism}

Saussure provided detailed insight into many aspects. By identifying the 'langue' and the 'parole' from what was en block regarded as language, Saussure opened the way to finer perceptions, differently oriented. This approach has been generally evaluated in the field of language. Although not so interpreted, Saussure seems to have anticipated the debate between constructivism and inneism. This positing may open to a complementary argument to support constructivism. The dichotomy of langue-parole is an earlier statement related to the question of transfer of structures. By positing it this way, Saussure is in favor of language structures arising from and relying on the process - the parole. Sassure also linked it to the community speaking the language: certain initiatives may arise from the parole, which pass onto the language structure only if satisfying a few conditions, including the acceptance by the community. The language is a property of the community and they seem to have their say with regard to accepting what patterns and structure initiatives. As such, initiatives arise from the process of languaging (parole) and are accepted through this process, by the community of speakers. This runs counter to the nativist claim of structures being pre-wired and developed from internal structuring.

Structuralism and constructivism seem to agree on several issues. What is more, structuralism, although initiated decades prior to the rise of constructivism, offers complementary arguments to support, to explain and develop particular constructivist claims. It should be mentioned that constructivist ideas are but implicit reading within structuralism. No such mention ever is to be found or developed in this spirit. This could be due to two reasons: i) that constructivist approach had not yet been articulated, and ii) structuralism on its own, was breaking new ground; it had its own concerns, to establish the basics and to introduce a very different pattern of thinking in linguistics.

Although Saussure introduced the smart distinction between langue and parole, he did not proceed further to establish the links and the bridges between the two, how they communicate, how langue is supplied and molded on the inputs and patterns as supplied from, and occurring in the parole. Even constructivism, did not dwell in 'such waters'. Until 1975, there were no significant projections of constructivism onto language studies.

Another interesting notion is that of distribution, introduced by Bloomfield 5 . He applied it mainly in semantics, and could not develop the pattern underlying every linguistic sign and structure. As a notion, it provides a more material basis to the evolution of structures, with insightful hints that such could be the basis of supply to the establishment of structures.

Structuralists were generally open-minded and little biased, allowing green light to their linguistic and scientific intuition, providing themselves proper access to language facts. The first half of the last century saw a variety of ideas and proposition, many of which were not further developed or elaborated. But structuralism (in linguistics) may still offer valuable contribution through such raw matter.

Sapir is among the authors little explored for his inputs and contributions. He is outstanding with his far-going assumptions, particularly that of linguistic relativism, which posits that the language a person speaks has an influence on this person's cognition. It is often termed the 'Sapir-Whorf hypothesis'.

Martinet is another well known author, whose argument seems to be inclined to what is being claimed nowadays by constructivism (versus inneism \& generativism). He advanced the idea of the arbitrariness in the language earlier launched by Saussure, and considered language as a means of communication where human experience is analyzed and formalized in different ways by the communities of speakers. In the course of evolution, the communities of speakers organize their experiences in their arbitrary contexts, which is then reflected in the kind of structures developed. Martinet also favors the idea of language changing just because and in the course of its functioning. Hence, he links the structuring of the language to its processing, to the process itself, positing it as the ground on which the evolution and the structuring is being fed.

\section{Constructivism in language studies}

In 1975, in the well-known debate between Chomsky and Piaget, Palmerini observed that there is not going to be a constructivist grammar. However, the generative views have been largely contested in the recent years. The most

${ }^{5}$ Leonard Bloomfield, is within structuralism, his main work is "Language" (Bloomfield, 1933) 
significant of the opposite views, are not explicitly related to constructivism, but the very name of Construction Grammar 6 , does not sound irrelevant to the Piagetian theory.

The early principles of Construction Grammar have been contributed by Adele Goldberg. Basically, she posits that elements in the language "involve pairings of form with semantic or discourse function". She defines as such that: "any linguistic pattern is recognized as a construction as long as some aspect of its form or function is not strictly predictable from its component parts or from other constructions recognized to exist.'

In another publication Goldberg (2006) emphasizes the focus on the surface form, stating disapproval with the approach of derivations and transformations of language structures, which is essential in the generativist approach. Goldberg considers elements as constructions and these constructions internally form a network. The cognitive processes do have their say in the formation of the language structures, including the language abstractions. Constructions are understood to be learned on the basis of the input and general cognitive mechanisms, thus excluding any consideration of pre-wired structures in the human brain.

Michael Tomasello has supported a non-inneistic view regarding the language acquisition and structuring. $\mathrm{He}$ conceives linguistic competence as the end state of the learning process. While Chomsky considers the language structures as pre-wired, Tomasello believes that the acquisition of the language structures is a process of construction. Children receive facts about how sentences are used by speakers to fulfill their communicative intentions. The semantic and contextual information is also used by children for the purposes of acquiring grammatical knowledge (Tomasello, 2003).

The argument relates to whether the children have pre-wired language structures. Generativism relies on the "Poverty of the Stimulus" argument, whereas Tomasello argues that children learn language without the aid of any inborn linguistic information. What the children (babies) avail of is not language-specific structures, but perceptual and cognitive skills. Hence it is a question of where to draw the line, concerning the pre-wired structures, whether they are cognitive or linguistic.

\section{Relevant findings in neuroscience}

Neurosciences could be a missing link in the overall challenge to acquiring a proper insight into the establishment and development of our cognition structures, language structures included. Even Chomsky states that language sciences still lag behind with regard to this concern. Construction grammar also favors that the constructions attempted in language have to be proper and adequate to fit into neurobiological frames and molds.

Greenfield (Greenfield, 1995), emphasizes the neuronal processing in the form of neuronal assemblies, which are such that make each individual idiosyncratic in his or her mental processing. The synaptic connections and networking is the output of traces of individual experiences.

Neuroscientists have introduced insightful concepts that may inform the linguistic insight. The structuring of grammatical and other constructions may need to refer to mechanisms and processes described by neuroscientists. Such are for instance the LTP (Long-Term-Potentiation), or the mirror neurons. Linguists can make use of such means to explore the structuring of language, especially in the particularities where such specific notions and neuronal means can reveal themselves in action. Linguists may need to consider how the neuronal assemblies are formed, in what particular conditions, and how LTP works in view of the language constructions.

Mirror neurons have been claimed by a Parma group of researchers ${ }^{7}$. There is evidence that such neurons are to be found in humans too. Some researchers believe that this type neurons are responsible for and enable our interrelations with other individuals. When it comes to language, there is need to provide a neuro-biological account of how grammatical patterns evolve from what similar existing ones, how these spread and the extent and the border these can expand. For the moment these are not being taken up by linguistics. If so considered, language studies may offer a complementary view of how neuro-biological structures are established and how these evolve in what environments.

The need for referring to the neuronal mechanisms to understand language structure has long been articulated (Chomsky, Construction grammar), although it seems rather early yet.

\footnotetext{
${ }^{6}$ Construction Grammar was launched in the 1980's by well-known authors like: George, Lakoff, Charles Fillmore, Paul Kay.

$7 \mathrm{fMRl}$, transcranial magnetic stimulation, single cell recordings
} 


\section{Reference}

Akademia e Shkencave. (2002). Gramatika e gjuhes shqipe Vellimi I, Morfologjia. Tirane:

Bloomfield, L. (1933). Language. Chicago: University of Chicago Press.

Bronckart, J.-P. (1977). Théories du langage: une introduction critique. Liege, Belgium: Pierre Mardaga.

Chomsky, N. (1965). Aspects of the Theory of Syntax. Cambridge, MA: : MIT Press.

Chomsky, N. (1987, Fall). Language, Language Development and Reading. Reading Instruction Journal .

Cowie, F. (2010, Summer ). Innateness and Language. Retrieved from The Stanford Encyclopedia of Philosophy, Edward N. Zalta (ed.): $<$ http://plato.stanford.edu/archives/sum2010/entries/innateness-language/>.

Ducrot, O. (1973). Le structuralisme en linguistique. Seuil: Points .

Fillmore, C. J. (1975). An Alternative to Checklist Theories of Meaning. Proceedings of the First Annual Meeting of the Berkeley Linguistics Society, (pp. 123-131).

Fillmore, C. J. (1968). The Case for case. In R. a. Holt, Universals in Linguistic Theory (pp. 1-88). New York: Bach and Harms.

Fillmore, C. J. (1977). The case for case reopened. In P. C. Sadock, Syntax and Semantics: Grammatical Relations, Volume $8, . \therefore$. (pp. 59-91). New York: Academic Press.

Fillmore, C. J. (1988). The Mechanisms of "Construction Grammar". Proceedings of the Fourteenth Annual Meeting of the Berkeley Linguistics Society, (pp. 35-55).

Gallese, V. (2009, 19(5)). Mirror neurons, embodied simulation, and the neural basis of social identification. Psychoanalytic Dialogues , pp. 519-536.

Gallese, V., C. Keysers, and G. Rizzolatti. (2004, 8(9)). A unifying view of the basis of social cognition. . Trends in Cognitive Sciences , pp. 396-403.

Goldberg, A. (2003, May No.5). Constructions: a new theoretical approach to language. TRENDS in Cognitive Sciences Vol.7 2003 .

Goldberg, Adele E., \& Casenhiser, Devin. (2006). Learning Argument Structure Constructions. . In C. f. Language, Constructions in Acquisition . (pp. (pp. 185-204)). Stanford: E. Clark \& B. Kelly (Eds.),.

Keysers, C., and V. Gazzola. (2009). Mirror Neuron Systems. Humana , 1-35.

Linell, P. (2011 - adapted in 2013). CHOMSKYANISM - FROM INNOVATION TO IRRELEVANCE. drawn from http://www.liu.se/ikk/medarbetare/perlinell?l=sv .

Martinet, A. (1962). A functional view of the language. Oxford: Clarendon Press.

Martinet, A. (1960). Éléments de linguistique générale. Paris: Armand Colin.

Palmer, F. R. (1974). The English Verb. London: Longman Group Limited.

Palmer, K. (2004). General Schemas Theory. Retrieved February 3, 2015, from Holonomic Net: http://www.holonomic.net/gs00a04.pdf

Piatelli-Palmerini, M. (1980). Language and Learning; The debate between Jean Piaget and Noam Chomsky. Cambridge, Massachusets: Harvard University Press.

Piattelli-Palmarini, Massimo. (20-21 May, 1974). A debate on bio-linguistics, Centre Royaumont pour une science de l'homme report. Endicott House Dedham, Massachusetts.

Rizzolatti, G., and L. Craighero. (2004, 27(1)). The mirror-neuron system. Annual Review of Neuroscience .

Sapir, E. (1921). Language: An Introduction to the Study of Speech. New York: Harcourt, Brace.

Saussure, F. d. Course in General Linguistics.

Tomasello, M. ((in press)). Constructing a language: A usage-based theory of Language Acquisition, . Harvard: Harvard University Press. 